\title{
Institucionalização de práticas integrativas e complementares no Sistema Único de Saúde!?
}

\author{
Institutionalization of integrative, complementary \\ practices in Sistema Único de Saúde!?
}

Santa Maria, 17 de abril de 2013.

Prezados editores,

Já se vão sete anos de aprovação da portaria do Ministério da Saúde n.971/2006, que criou a Política Nacional de Práticas Integrativas e Complementares (PNPIC) no Sistema Único de Saúde (SUS). Para os simpatizantes, os praticantes e a população em geral pode-se dizer que houve um avanço - instituiu-se o que vem fazendo parte, de uma forma ou de outra, da vida da sociedade brasileira desde sempre (uso de práticas de cura alheias, ou avessas, à medicina hegemônica). Com efeito, a referida portaria instituiu no SUS a homeopatia, a acupuntura, a fitoterapia, o termalismo e a medicina antroposófica, depois de ouvidos 5.560 municípios que já faziam, de alguma maneira, uso dessas práticas. Assim, algumas práticas de cura do que se conhece popularmente como medicina alternativa foram aceitas pelo establishment responsável pela saúde no Brasil. Se não, vejamos.

Comentando rápida e grosseiramente as cinco práticas (para usar o próprio nome da política), observa-se que, à exceção da homeopatia, as outras quatro são quase desconhecidas não só dos próprios gestores de saúde - conforme salienta trabalho recente de Galhardi, Barros e Leite-Mor ${ }^{1}$ - como da maioria da população que utiliza os serviços do SUS. Ressalvese que o trabalho citado refere-se à homeopatia, cuja prática exatamente se afirma ser a mais conhecida das cinco escolhidas para fazer parte daquela política de saúde. O que se poderia dizer a respeito de acupuntura, fitoterapia, termalismo e medicina antroposófica? Numa resposta rápida, e quase que em uma vertente decrescente, da primeira à última, pode-se dizer que fazem parte da vida de um número ínfimo dos usuários de saúde no Brasil.

Até este momento, não se tem conhecimento de estudos que deem conta da implantação da PNPIC em todos os estados brasileiros. Sabe-se que no Rio Grande do Sul há uma comissão criada para dar andamento a sua institucionalização de fato, mas os trabalhos são muito recentes, sem nenhum encaminhamento definido.

\footnotetext{
1 Wania Maria Papile Galhardi, Nelson Filice de Barros e Ana Cláudia Moraes Barros Leite-Mor, "O conhecimento de gestores municipais de saúde sobre a Política Nacional de Prática Integrativa e Complementar e sua influência para a oferta de homeopatia no Sistema Único de Saúde local", Ciência e Saúde Coletiva, Rio de Janeiro, v.18, n.1, p.213-220, 2013.
} 
Como já dito, a criação da PNPIC deve ser saudada, mas não há como não mostrar preocupação a respeito de sua institucionalização. Não bastam boas intenções e livretos distribuídos gratuitamente pelo Ministério da Saúde explicando a política. O que está em jogo para o seu efetivo funcionamento no SUS é uma discussão político-epistemológica estabelecida nos bastidores e que se espraia pelo ar, ou seja, um embate que se pode observar entre coletivos de pensamento, para usar a epistemologia de Ludwik Fleck. Dificuldades de toda ordem se colocam para sua implementação ${ }^{2}$, mas aqui aponta-se para, talvez, a mais preocupante, porque provavelmente a mais impeditiva - o poder da biomedicina hegemônica travestida na autoridade máxima para arbitrar sobre a saúde humana. Para fins desta carta, fiquemos apenas com a homeopatia, aceitando ser a mais conhecida pela população brasileira, e a que está entre nós desde o início do século XIX, portanto, há mais tempo.

A homeopatia, desde sua introdução no Brasil, experimenta um processo de recuos e avanços no que diz respeito a sua institucionalização/legitimidade. Assim, até hoje houve fases de expansão e outras de recolhimento da comunidade homeopata, e isto se deve, entre outras coisas, ao fato de a medicina alopata advogar para si o poder de que goza porque legitimada pela ciência. Lembrando que as próprias escolas de medicina não têm clareza sobre um conjunto de conceitos fundamentais que dão, efetivamente, condições para uma disciplina se caracterizar como ciência, concorda-se com o que segue:

É este feixe algo caótico de fragmentos de discurso científico, carente de organicidade, que serve de suporte a uma prática historicamente intolerante com suas concorrentes, às quais acusa de 'não científicas', como se ela própria fosse. E é, ela mesma, um emaranhado igualmente desarticulado em que se misturam várias peças dissimétricas que incluem em proporções variadas tradição, ciência, pressão das indústrias farmacêutica e de equipamentos e larga margem de incerteza. ${ }^{3}$

Por outro lado, embora a homeopatia tenha sido reconhecida como especialidade médica pelo Conselho Federal de Medicina em 1980, sabe-se que é tida entre os médicos em geral como uma filha bastarda, a quem se permite a convivência, mas não a interação familiar. Afinal, a homeopatia "ainda" não é reconhecida como científica, e a medicina instituída não aceita outra racionalidade que não seja a sua. No entanto, pode-se observar um movimento, entre alguns homeopatas, no sentido de buscar cientificidade através de meta-análises, método epidemiológico de aferir evidências e desfechos em vários estudos clínicos. A pergunta que fica é a seguinte: como utilizar o mesmo caminho metodológico para aferir racionalidades tão distintas como são a alopatia e a homeopatia? Ademais, por que enquadrar a homeopatia na racionalidade da biomedicina? Não seria mais pragmático, a fim de ir ao encontro das necessidades de saúde da população brasileira, já tão desamparada nesse quesito, simplesmente aceitar que a homeopatia comporta em si outra racionalidade médica?

\footnotetext{
${ }^{2}$ Charles Dalcanale Tesser e Nelson Filice de Barros, "Medicalização social e medicina alternativa e complementar: pluralização terapêutica do Sistema Único de Saúde”, Revista de Saúde Pública, São Paulo, v.42, n.5, p.914-920, 2008.

${ }^{3}$ Kenneth Rochel de Camargo Júnior, Biomedicina, saber e ciência: uma abordagem crítica, São Paulo, Hucitec, 2003, p.74.
} 
Retomando a ideia inicial, pode-se concluir que a PNPIC deu início a uma tarefa árdua, qual seja a de lidar com relações de poder sobre o conhecimento que se estabelecem entre a biomedicina instituída e as práticas integrativas e complementares, embora talvez a maior resistência fique mesmo com a homeopatia. A acupuntura parece ter mais aceitação entre os médicos; fitoterapia e termalismo (pela sua própria terapêutica não invasiva) não entrariam em rota de colisão científica com eles, e a medicina antroposófica pode-se dizer que é rigorosamente desconhecida da massa populacional brasileira usuária do SUS. E provavelmente, por ser a mais desconhecida, seja a que menos rejeição sofra por parte da categoria profissional médica.

Finalmente, torçamos para que a PNPIC seja rapidamente instituída em todos os estados da federação a fim de que, acima dos embates político-epistemológicos, prevaleça o atendimento à carência por recursos de saúde, especialmente daqueles pertencentes aos estratos mais baixos da população.

Fátima Cristina Vieira Perurena Professora, Departamento de Ciências Sociais/ Universidade Federal de Santa Maria.

P.S. [de 17.3.2014]: no dia 20 de dezembro de 2013 foi aprovada a Política Estadual de Práticas Integrativas e Complementares (Pepic-RS), através da resolução CIB 695/13. O documento, além de tratar das cinco práticas previstas na portaria federal de 2006, inclui outras como terapia floral, práticas corporais como biodança, tai chi chuan, meditação, reiki, terapia comunitária, terapias manuais e manipulativas, yoga, shantalla, entre outros. 